\title{
Self-monitoring of blood glucose in noninsulin-treated type 2 diabetes: an overview
}

This article was published in the following Dove Press journal:

Diabetes, Metabolic Syndrome and Obesity:Targets and Therapy

8 September 2009

Number of times this article has been viewed

\author{
Nanne Kleefstra' \\ Johanna Hortensius' \\ Kornelis JJ van Hateren' \\ Susan JJ Logtenberg' \\ Sebastiaan T Houweling ${ }^{2}$ \\ Rijk OB Gans ${ }^{3}$ \\ Henk JG Bilo' \\ 'Diabetes Centre, Isala Clinics, \\ Zwolle, The Netherlands; \\ ${ }^{2}$ Langerhans Medical Research \\ Group, The Netherlands; \\ ${ }^{3}$ Department of Internal Medicine, \\ University Medical Center Groningen, \\ Groningen, The Netherlands
}

Introduction: The effectiveness of self-monitoring of blood glucose (SMBG) in noninsulin-treated patients with type 2 diabetes (T2DM) remains unclear. We aimed to review the trials investigating the effects of SMBG in this population.

Methods: Medline was searched until June 29, 2009. Randomized controlled trials (RCTs) of at least 12 weeks' duration were included. Data on the following aspects were gathered: patient and study characteristics, effects on $\mathrm{HbA}_{1 \mathrm{c}}$, quality of life and treatment satisfaction, and methodological quality.

Results: The search revealed 9 original RCTs. These studies were very heterogeneous, and 5 were classified as of high quality. The studies with the best methodology did not show an effect of SMBG on $\mathrm{HbA}_{1 \mathrm{c}}$, the studies with the worst methodological quality did. Two out of the 4 studies that assessed quality of life showed a significant change in favor of the control group, 1 study showed a significant change in favor of SMBG.

Discussion and conclusion: We found an inverse relation between study quality and efficacy of SMBG. At this moment, there is no basis for general use of SMBG in noninsulin-treated T2DM patients.

Keywords: blood glucose self-monitoring, diabetes mellitus, type 2, blood glucose, hemoglobin A, glycosylated

\section{Introduction}

Self-monitoring of blood glucose (SMBG) is an important tool in the management of diabetes mellitus. Patients with type 1 diabetes frequently measure their blood glucose to evaluate and, if necessary, to adjust insulin treatment and lifestyle, and to detect hypoglycemia. It is recommended that patients should measure their blood glucose at least 3 times daily. ${ }^{1}$ Although effectiveness of SMBG has been established for insulintreated patients with type 2 diabetes (T2DM), the optimal frequency and timing of SMBG have not yet been established. ${ }^{2,3}$ There is still much debate about the use and effectiveness of SMBG in noninsulin-treated T2DM. ${ }^{4}$ Many trials have investigated the effects of SMBG in this specific group and many (systematic) reviews have been written on this topic with conflicting conclusions. ${ }^{5}$

In insulin-treated patients SMBG can lead to (instant) insulin dose adjustments, thereby improving glycemic control and/or reducing episodes of hypoglycemia. This cascade is not applicable for patients not using insulin, because an instantaneously modifiable factor is lacking. Still, there are theoretically advantages of SMBG in this population as well. For instance, data of SMBG could be used during periodical consultation with the diabetes health care provider to start or titrate blood glucose-lowering agents.
Correspondence: Nanne Kleefstra Diabetes Centre, Isala Clinics, PO Box 10400, 8000 GK, Zwolle, The Netherlands

$\mathrm{Tel}+3 \mathrm{I}-38-42425 \mathrm{I} 8$

Fax +3I-38-4243367

Email kleefstra@langerhans.com 
Furthermore, based on the measured blood glucose, patients could adjust physical activity or food intake, or both.

Many aspects need to be considered when evaluating the effects of SMBG in noninsulin-treated patients. Firstly, how SMBG is used depends on the patient's level of diabetes education. Without any knowledge of the patient about the values to strive for it will be merely self-measurement and health care providers are needed to interpret the results and give advice on how to adjust physical activity and diet. Whereas, when the patient is fully informed about the treatment goals and is educated about how to achieve these goals, SMBG could function as a tool for self-regulation. Secondly, the frequency of measurements varies; SMBG can be performed infrequently or each day at fixed times, pre- or postprandial, or both. Thirdly, the population of noninsulin treated T2DM patients is heterogenic and may use SMBG differently. For example, newly diagnosed patients, who just started a specific diet versus patients on a maximum dosage of oral blood glucose-lowering agents, when insulin therapy will have to be the next step. Or patients in good glycemic versus patients in persistent poor glycemic control. Fourthly, in some situations the primary goal of the patient and the health care provider could not be to improve glycemic control with SMBG, but to improve the patient knowledge of diabetes and the effects of different behavior on glucose levels and thereby influencing nonclinical factors such as well-being and treatment satisfaction. Furthermore, performing SMBG includes the patient drawing blood from his or her finger tip regularly. This procedure can be painful or frightening and may also have its impact on well-being on its own.

We aimed to review trials investigating the effects of SMBG in noninsulin-treated patients with T2DM. We did not focus only on the effects on glycemic control, but also on the effects on health-related quality of life and treatment satisfaction as well as on the methodological quality of the trials.

\section{Methods}

\section{Inclusion criteria of studies}

Randomized controlled trials (RCTs) of at least 12 weeks' duration were included for this review. These studies should have included noninsulin-treated patients with T2DM, the intervention group should use SMBG, and the control group should use any other form of measurement of glycemic control or should continue to receive usual care. Trials should have included measurements of glycosylated hemoglobin $\left(\mathrm{HbA}_{1 \mathrm{c}}\right)$.

\section{Search strategy}

Medline was searched until June 29, 2009 using PubMed with the following combination of free text words and MeSH-terms:

(((self-measur* OR self-monitor*) OR ("Blood Glucose Self-Monitoring"[Mesh])) AND (("Diabetes Mellitus"[Mesh]) OR (diabete* OR diabeti* OR diabeto*)))) AND (((randomized controlled trial[Publication Type] OR (randomized[Title/Abstract] AND controlled[Title/ Abstract] AND trial[Title/Abstract]))) OR systematic[sb].

Articles were selected for full text reading based on their title and abstract by two of the authors (NK and JH). The references of the systematic reviews were checked for additional studies as well.

\section{Data selection}

The selected RCTs were carefully read and data on the following topics were gathered systematically by two of the authors (NK and $\mathrm{KJJH})$ : patient characteristics, treatment modality, duration of intervention and control, type of intervention and control, and the number of patients in each treatment arm. Data on changes in $\mathrm{HbA}_{1 \mathrm{c}}$ and quality of life and treatment satisfaction were extracted both within and between treatment groups. Methodological quality of the trials was assessed using the same method as Welschen et al used in their Cochrane review. ${ }^{4}$ Eleven items pertaining to internal validity were applied:

1. Was the method of randomization adequate?

2. Was the treatment allocation concealed?

3. Were the groups similar at baseline regarding the most important prognostic indicators?

4. Was the patient blinded to the intervention?

5. Was the care provider blinded to the intervention?

6. Was the outcome assessor blinded to the intervention?

7. Were co-interventions avoided or similar?

8. Was the compliance acceptable in all groups?

9. Was the withdrawal/drop-out rate described and acceptable?

10. Was the timing of the outcome assessment in all groups similar?

11. Did the analysis include an intention-to-treat analysis?

Each item had a rating scale of "yes", "no" or "don't know". Studies fulfilling 6 or more of the 11 quality criteria were considered to be of "high quality". All studies scoring less than 6 of the criteria were rated as "low quality". Studies of low methodological quality were not excluded. 


\section{Results}

\section{Studies}

The initial search identified 427 publications, of which 31 papers were selected for full text reading based on title and abstract. These 31 studies included 17 potential systematic reviews and 14 potential RCTs. From the RCT selection, 1 trial was excluded because of the inclusion of patients using insulin. ${ }^{6}$ In 2 studies, the intervention as well as the control group used SMBG. ${ }^{7,8}$ For 1 study 2 references ${ }^{9,10}$ were found and for another study 3 references were found. ${ }^{11-13}$ One additional $\mathrm{RCT}^{14}$ was selected from the reference list of a systematic review. ${ }^{15}$ Consequently, 9 original RCTs were selected and will be discussed. ${ }^{9-14,16-21}$ Both authors ( $\mathrm{NK}$ and $\mathrm{JH}$ ) obtained the same results for the literature search. Of the 17 potential systematic reviews, 14 references qualified. ${ }^{4,15,22-33}$ Four references, however, were all based on the Cochrane review of Welschen et al. ${ }^{4,24,27,28}$ Two references were based on the review of Coster et al..$^{31,32}$

\section{Patient characteristics and treatment modality (see Table I)}

The included trials were almost all performed in Western Europe or the United States. One study included patients from several Eastern Europe countries and from Malaysia and Iran. ${ }^{14}$ Except for the study of Farmer et al ${ }^{11-13}$ all studies included patients in poor glycemic control indicated by $\mathrm{HbA}_{1 \mathrm{c}}$ values ranging from $8.1 \%$ to $12.0 \%$ (mean values). The study by O'Kane et al included only patients with new onset diabetes. ${ }^{21}$ The duration of diabetes in the other studies ranged from 2.8 to 12.7 years. The majority of the included patients was treated with oral blood glucose-lowering agents. Furthermore, most patients were obese, and did not use or infrequently used SMBG prior to the study.

\section{Study characteristics (see Table 2)}

All studies had a duration of 24 weeks or longer, with the longest study duration being 12 months. Studies differed substantially regarding requested number of blood glucose values, ranging from 6 to 42 times a week, with most studies collecting some postprandial values. Patients in most studies received target glucose values to strive for. These targets were different between studies, and more recent studies used lower target values. Glucose values were mostly part of collected information which was used to give advice on lifestyle responses. In 4 studies strict algorithms were used to adjust blood glucose-lowering therapy. ${ }^{14,16,17,21}$ From the published data from the remaining
5 studies it is not clear whether and if so on what basis therapy was adjusted. ${ }^{9-13,18-20} \mathrm{~A}$ dietician participated in most studies or specific advices about diet were given (in 1 study education about counting carbohydrates was given). Patients in the less intensive SMBG group of the study by Farmer et al did not receive such advice. ${ }^{11-13}$ In some studies much time and effort of a multidisciplinary team was invested to support the patient with SMBG, while in another study SMBG was given to the intervention group without support or education. In 2 studies, the control group performed urine testing of blood glucose. ${ }^{16,18}$ In other studies usual care was continued or $\mathrm{HbA}_{1 \mathrm{c}}$ was measured periodically in the control group. In the studies by Allen, Davidson, Fontbonne, Guerci, and in the less intensive group in the study by Farmer, it appears that except performing SMBG or not, no differences exist between the intervention and control group. ${ }^{11-13,16-19}$ In other studies, the SMBG group received also additional information or got personal advice about diet and exercise.

\section{Methodological quality of studies (see Table 3)}

Four studies were of low quality, 5 studies were of high quality. The studies published by Farmer, Davidson, and O'Kane are the studies with the best methodology. However, all these studies had problems with the compliance of patients performing SMBG. ${ }^{11-13,17,21}$ In the study by Davidson et al compliance was less than $50 \% .{ }^{17}$ The study described by Farmer et al reached compliance rates of $67 \%$ and $52 \%$ in the less and more intensive intervention groups, respectively. In the study by O'Kane et al $34 \%$ of the patients performed less than $80 \%$ of the requested measurements.

\section{Effect on glycemic control (see Table 4)}

Three studies found a significant beneficial effect on $\mathrm{HbA}_{1 \mathrm{c}}$ of SMBG compared to the control group. ${ }^{9,10,19}$ In the study by Guerci et al $\mathrm{HbA}_{1 \mathrm{c}}$ decreased from $9.0 \%$ to $8.1 \%$ after 6 months. This decrease in $\mathrm{HbA}_{1 \mathrm{c}}$ was $\sim 0.3 \%$ more compared to the decrease in found in the control group $(P=0.009)$. In the study by Schwedes et al $\mathrm{HbA}_{1 \mathrm{c}}$ decreased from $8.5 \%$ to $7.5 \%$, which was $\sim 0.5 \%$ ( $95 \% \mathrm{CI}-0.77,-0.11)$ more compared to the control group. In the study by Barnett et al $\mathrm{HbA}_{1 \mathrm{c}}$ decreased from $8.12 \%$ to $6.95 \%$, which was $0.24 \%(95 \% \mathrm{CI}-0.45,-0.03)$ more compared to the control group. ${ }^{14}$ Muchmore et al found a nonsignificant benefit of SMBG of $\sim 0.7 \% .{ }^{20}$ In the other studies nonsignificant differences between SMBG and control groups were between $-0.2 \%$ and $0.1 \%$. 


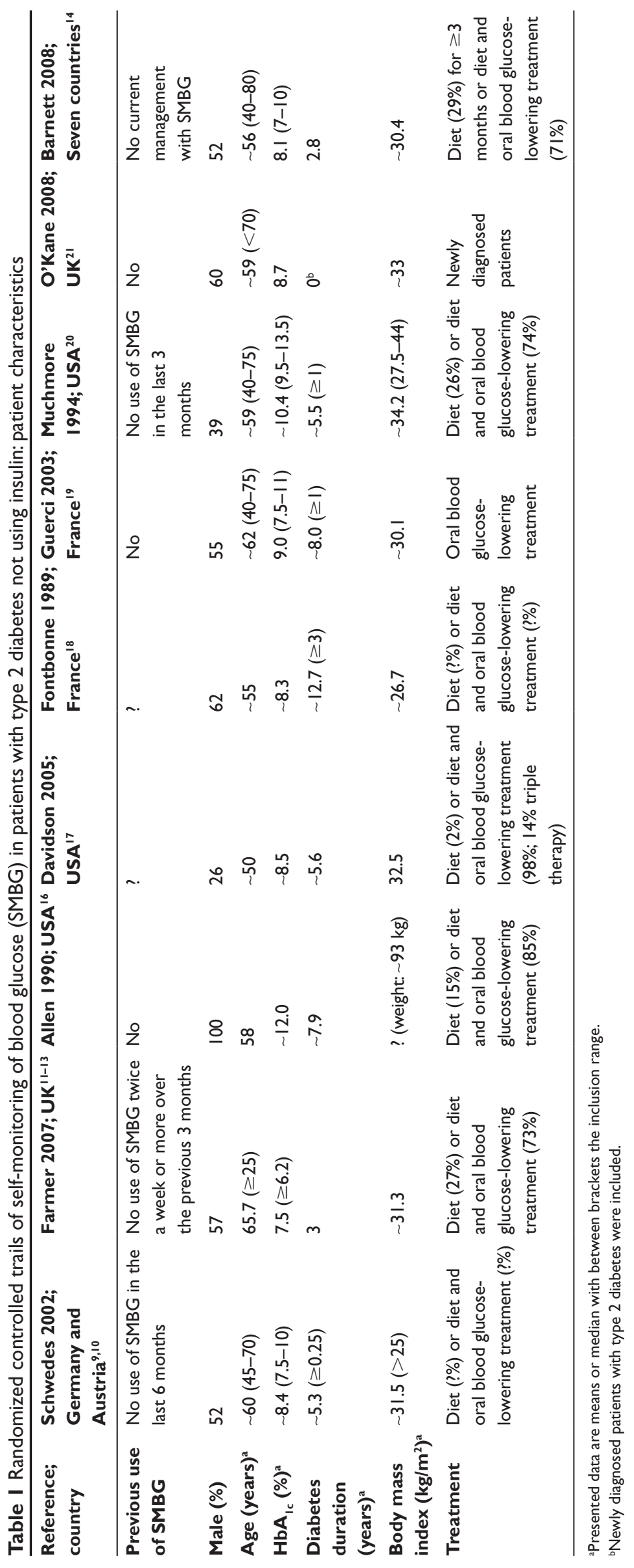


Table 2 Randomized controlled trails of self-monitoring of blood glucose (SMBG) in patients with type 2 diabetes not using insulin: study characteristics

\begin{tabular}{|c|c|c|c|c|}
\hline \multirow[t]{2}{*}{ Study } & \multirow[t]{2}{*}{ Duration } & \multicolumn{2}{|l|}{ Treatment arm } & \multirow{2}{*}{$\begin{array}{l}\text { Number } \\
\text { of patients } \\
\text { Intervention/ } \\
\text { Control }\end{array}$} \\
\hline & & Intervention & Control & \\
\hline Schwedes ${ }^{9,10}$ & 24 weeks & $\begin{array}{l}\text { SMBG } 6 \text { times a day (pre- and I hour postprandial } \\
\text { values), } 2 \text { days a week } \\
\text { (I week day and Sunday) } \\
\text { Documentation of eating habits } \\
\text { Documentation of state of well-being } \\
\text { Patients were explained that combined information } \\
\text { allowed them to make diet and lifestyle changes in order } \\
\text { to improve glycemic control counseling to increase } \\
\text { self-perception, to promote self-reflection and to } \\
\text { enhance self-regulation } \\
\text { Therapy adjustment? }\end{array}$ & $\begin{array}{l}\text { Nonstandardized counseling with a } \\
\text { focus on diet and lifestyle } \\
\text { Therapy adjustment? }\end{array}$ & $113 / 110$ \\
\hline Farmer ${ }^{11-13}$ & 12 months & $\begin{array}{l}\text { I. Less intensive } \\
\text { SMBG } 3 \text { times a day ( } \mathrm{l} \text { fasting and } 2 \text { pre- or postprandial } \\
\text { values), } 2 \text { days a week } \\
\text { Strive for preprandial glucose concentrations of } \\
4-6 \mathrm{mmol} / \mathrm{l} \text { and postprandial } 6-8 \mathrm{mmol} / \mathrm{L} \\
\text { A diary was used to record goals, activities, } \\
\text { and blood glucose results } \\
\text { No information about how to interpret glucose values } \\
\text { was given } \\
\text { Therapy adjustment? } \\
\text { 2. More intensive } \\
\text { In addition to 'I. less intensive': } \\
\text { Training and support in timing, interpretation and using } \\
\text { results also to enhance motivation and maintain adher- } \\
\text { ence to diet, physical activity and drug regimens } \\
\text { Encouragement to experiment with SMBG to explore } \\
\text { the effects of specific activity } \\
\text { Therapy adjustment? }\end{array}$ & $\begin{array}{l}\text { A diary was used to record self-care } \\
\text { goals and strategies for achieving them } \\
\text { Usual (standardized) care } \\
\text { Information about eating and physical activity } \\
\text { Therapy adjustment? }\end{array}$ & $150 / 151 / / 52$ \\
\hline Allen $^{16}$ & 6 months & $\begin{array}{l}\text { SMBG before meals every other day, at least } 36 \text { times } \\
\text { a month Strive for glucose concentrations }<7.7 \mathrm{mmol} / \mathrm{L} \\
\text { fasting and }<8.8 \mathrm{mmol} / \mathrm{L} \text { before lunch and dinner } \\
\text { Algorithm to adjust blood glucose-lowering treatment } \\
\text { Instructed by dietician about diet, fiber intake, ideal } \\
\text { bodyweight, activity level }\end{array}$ & $\begin{array}{l}\text { Urine testing before meals every other } \\
\text { day, at least } 36 \text { times a month Strive for } \\
\text { negative urine checks } \\
\text { Algorithm to adjust blood } \\
\text { glucose-lowering treatment. Instructed } \\
\text { by dietician about diet, fiber intake, ideal } \\
\text { body weight, activity level }\end{array}$ & $27 / 27$ \\
\hline Davidson $^{17}$ & 6 months & $\begin{array}{l}\text { SMBG before and between I-2 hours after meals during } 6 \text { days } \\
\text { a week; } 2 \text { times breakfast, } 2 \text { times supper and } 2 \text { times dinner } \\
\text { Record meals } 5 \text { visits to dietician; education about meal } \\
\text { size and components on rise of postprandial glucose values } \\
\text { Strive for glucose concentrations }<7.15 \mathrm{mmol} / \mathrm{L} \\
\text { Algorithm to adjust blood glucose-lowering treatment }\end{array}$ & $\begin{array}{l}\text { Visits to dietician; education about } \\
\text { meal size and components on rise of } \\
\text { postprandial glucose values } \\
\text { Algorithm to adjust blood } \\
\text { glucose-lowering treatment }\end{array}$ & $43 / 45$ \\
\hline Fontbonne ${ }^{18}$ & 6 months & $\begin{array}{l}\text { SMBG twice every other day; fasting and } 2 \text { hours after } \\
\text { dinner and on Sundays after lunch } \\
\text { Consulting physician was allowed to adjust therapy }\end{array}$ & $\begin{array}{l}\text { I. Urine testing twice every other day; } \\
\text { fasting and } 2 \text { hours after dinner and on } \\
\text { Sundays after lunch } \\
\text { Consulting physician was allowed to } \\
\text { adjust therapy } \\
\text { 2. Every } 2 \text { months } \mathrm{HbA}_{\mathrm{Ic}} \text { testing with } \\
\text { physician's comment about metabolic } \\
\text { control to patient } \\
\text { Consulting physician was allowed to } \\
\text { adjust therapy }\end{array}$ & $68 / 72 / 68$ \\
\hline
\end{tabular}


Table 2 (Coutinued)

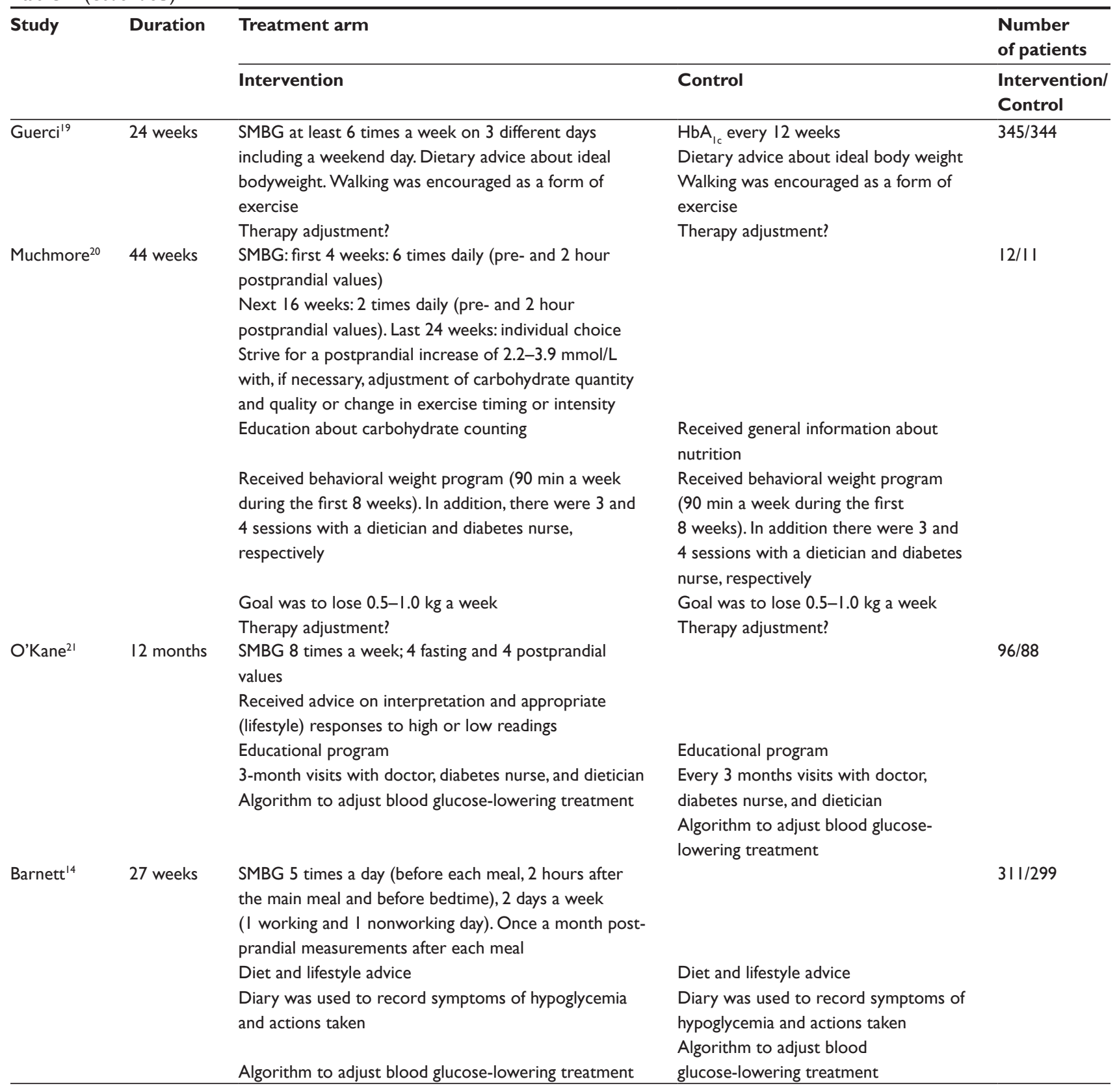

\section{Effect on quality of life and treatment satisfaction (see Table 5)}

In 4 studies, quality of life and treatment satisfaction were assessed using questionnaires. In the study of Muchmore et al no differences in quality of life were found between the intervention (SMBG) and control group (usual care). ${ }^{20}$ Although no significant difference was found for the total score on the patient well-being questionnaire in the study by Schwedes et al, 2 sub items ("depression" and "lack of well-being") improved with SMBG compared to control. ${ }^{9,10}$ In contrast with these findings, 2 more recent trials reported that SMBG was associated with lower quality of life. ${ }^{11-13,21}$ In the study by Farmer et al quality of life, as measured with the EQ-5D questionnaire, was lower in the more intensive intervention group compared to the control group. ${ }^{11-13}$ In the study by O'Kane et al the depression scale of the well-being questionnaire was significantly worse in the SMBG group compared to the control group. ${ }^{21}$ No differences were found concerning treatment satisfaction.

\section{Discussion and conclusion}

Nine RCTs investigating the efficacy of SMBG in noninsulin-treated patients with T2DM have been published 
Table 3 Randomized controlled trails of self-monitoring of blood glucose (SMBG) in patients with type 2 diabetes not using insulin: methodological quality

\begin{tabular}{|c|c|c|c|c|c|c|c|c|c|}
\hline Criteria & Schwedes ${ }^{9,10}$ & Farmer ${ }^{11-13}$ & Allen $^{16}$ & Davidson ${ }^{17}$ & Fontbone $^{18}$ & Guerci I' & Muchmore $^{20}$ & O'Kane $^{2 I}$ & Barnett $^{14}$ \\
\hline Randomization adequate & + & + & + & + & + & + & + & + & + \\
\hline Treatment allocation concealed & & + & - & & & & & - & + \\
\hline Groups similar at baseline & + & + & + & + & + & + & + & + & + \\
\hline Patient blinded & NA & NA & NA & NA & NA & NA & NA & NA & NA \\
\hline Care provider blinded & NA & NA & NA & NA & NA & NA & NA & NA & NA \\
\hline Outcome assessor blinded & & $+/ ?^{\mathrm{a}}$ & & & & & & $+/ ?^{\mathrm{a}}$ & \\
\hline Co-interventions avoided & - & + & + & + & & + & & + & + \\
\hline Compliance acceptable & + & - & + & - & + & & + & - & \\
\hline $\begin{array}{l}\text { Withdrawal/drop-out rate } \\
\text { acceptable }\end{array}$ & + & + & + & + & + & - & + & + & + \\
\hline $\begin{array}{l}\text { Timing of outcome assessment } \\
\text { similar }\end{array}$ & + & + & + & + & + & + & + & + & + \\
\hline Intention to treat analyses & - & + & - & + & & + & & + & \\
\hline Total quality score & 5 & (7) 8 & 6 & 7 & 5 & 5 & 5 & $(6) 7$ & 6 \\
\hline Overall quality conclusion & Low & High & High & High & Low & Low & Low & High & High \\
\hline
\end{tabular}

${ }^{\mathrm{a}}$ Outcome assessor was only blinded for $\mathrm{HbA}_{\mathrm{Ic}}$.

Abbreviation: NA, not applicable.

so far. ${ }^{9-14,16-21}$ One third of the studies reported a positive effect of SMBG on $\mathrm{HbA}_{1 \mathrm{c}}$ ranging from a $0.2 \%$ to $0.5 \%$ decrease. None of the studies published found a negative effect of SMBG on $\mathrm{HbA}_{1 \mathrm{c}}$. The evidence is more conflicting about the effects on quality of life. SMBG, as discussed in the introduction, is a complex intervention, although one can debate whether or not SMBG should be classified as an intervention in patients who "only" self-monitor without any form of self-regulation.

The differences in patient and study characteristics are distinct and complicate direct comparison between the studies. For example, mean $\mathrm{HbA}_{1 \mathrm{c}}$ ranges from $7.5 \%$ to $12 \%$. Furthermore, timing and frequency of SMBG vary widely, some studies advise patients which values to strive for, some studies give advice how to achieve these goals, and in some studies patients receive additional help from a dietician or a diabetes specialist nurse. These large differences in study design illustrate the many different ways that SMBG is integrated in the management of noninsulin-treated patients with T2DM and make it almost impossible to draw a single overall conclusion about its effectiveness.

Regardless of the heterogeneity of the studies, it is remarkable that there is an inverse relationship between study quality on the one hand, and efficacy on glycemic control and quality of life parameters on the other. Only 1 study of high methodological quality found a significant

Table 4 Randomized controlled trails of SMBG in patients with type 2 diabetes not using insulin - study results: $\mathrm{HbA}_{\mathrm{Ic}}$

\begin{tabular}{|c|c|c|c|}
\hline \multirow[t]{2}{*}{ Study } & \multicolumn{3}{|c|}{ Treatment arm } \\
\hline & Intervention & Control & Intervention vs Control \\
\hline Schwedes 9111 & $8.47 \rightarrow 7.47$ & $8.35 \rightarrow 7.81$ & $-0.46(95 \% \mathrm{Cl}-0.77,-0.1 \mathrm{I})$ \\
\hline Farmer ${ }^{11-13}$ & $\begin{array}{l}1.7 .41 \rightarrow 7.28 \\
2.7 .53 \rightarrow 7.36\end{array}$ & $7.49 \rightarrow 7.49$ & $\begin{array}{l}\text { I. }-0.14(95 \% \mathrm{Cl}-0.35,0.07) \\
\text { 2. }-0.17(95 \% \mathrm{Cl}-0.37,0.03)\end{array}$ \\
\hline Allen ${ }^{16}$ & $12.4 \rightarrow 10.4$ & $11.7 \rightarrow 9.7$ & $\sim 0.0(P>0.95)$ \\
\hline Davidson ${ }^{17}$ & $8.5 \rightarrow 7.7$ & $8.4 \rightarrow 7.8$ & $-0.2(95 \% \mathrm{Cl}-1 . \mathrm{I}, 0.6)$ \\
\hline Fontbonne $^{18}$ & $8.2 \rightarrow \sim 7.8$ & $\begin{array}{l}\text { I. } 8.6 \rightarrow \sim 8.5 \\
2.8 .2 \rightarrow \sim 7.7\end{array}$ & $\begin{array}{l}\text { I. } \sim-0.2(\mathrm{NS}) \\
\text { 2. } \sim 0 . \mathrm{I}(\mathrm{NS})\end{array}$ \\
\hline Guerci $^{19}$ & $9.0 \rightarrow 8.1$ & $8.9 \rightarrow 8.4$ & $\sim-0.3(P=0.009)$ \\
\hline Muchmore ${ }^{20}$ & $10.29 \rightarrow 8.75$ & $10.45 \rightarrow 9.6$ & $\sim-0.7$ (NS) \\
\hline $\mathrm{O}^{\prime} \mathrm{Kane}^{21}$ & $8.8 \rightarrow 6.9$ & $8.6 \rightarrow 6.9$ & $-0.07(95 \% \mathrm{Cl}-0.38,0.25)$ \\
\hline Barnett $^{14}$ & $8.12 \rightarrow 6.95$ & $8.12 \rightarrow 7.20$ & $-0.24(95 \% \mathrm{Cl}-0.45,-0.03)$ \\
\hline
\end{tabular}


Table 5 Randomized controlled trails of self-monitoring of blood glucose (SMBG) in patients with type 2 diabetes not using insulin - study results: Quality of life and treatment satisfaction

\begin{tabular}{|c|c|c|c|c|}
\hline \multirow{2}{*}{$\begin{array}{l}\text { Study } \\
\text { Ist author }\end{array}$} & \multirow[t]{2}{*}{ Questionnaire } & \multicolumn{3}{|l|}{ Treatment arm } \\
\hline & & Intervention & Control & Intervention vs Control \\
\hline Muchmore $^{20}$ & Diabetes Quality-of-life inventory & & & NS \\
\hline \multirow[t]{6}{*}{ Schwedes 910} & I. Patient well-being questionnaire & & & \\
\hline & General well-being (total score) & & & NS \\
\hline & Subitem 'Depression’ & & & $\begin{array}{l}\text { Reduction in intervention } \\
\text { compared to control } P=0.032\end{array}$ \\
\hline & Subitem 'Lack of well-being' & & & $\begin{array}{l}\text { Reduction in intervention } \\
\text { compared to control } P=0.02\end{array}$ \\
\hline & 2. Diabetes Treatment Satisfaction & $27.6 \rightarrow 31.1$ & $27.0 \rightarrow 30.6$ & $\sim-0 . I(P=0.9)$ \\
\hline & Questionnaire (DTSQ) & & & \\
\hline \multirow[t]{6}{*}{ Farmer ${ }^{11-13}$} & I.DTSQ & I. $29.4 \rightarrow 29.7$ & $29.3 \rightarrow 30.0$ & NS \\
\hline & & 2. $29.7 \rightarrow 30.1$ & & \\
\hline & 2. W-BQI2 & I. $24.3 \rightarrow 24.5$ & $25.1 \rightarrow 25.9$ & NS \\
\hline & & $2.25 .2 \rightarrow 24.9$ & & \\
\hline & 3. EQ-5D & I. $0.78 \mathrm{I} \rightarrow 0.755$ & $0.799 \rightarrow 0.798$ & $-0.029(95 \% \mathrm{Cl}-0.084,0.025)$ \\
\hline & & 2. $0.807 \rightarrow 0.733$ & & $-0.072(95 \% \mathrm{Cl}-0.127,-0.017)$ \\
\hline \multirow[t]{6}{*}{ O'Kane ${ }^{21}$} & I. Well-being questionnaire & & & $6.05(p=0.011)$ \\
\hline & depression (I of the subitems, & & & \\
\hline & other NS) & & & \\
\hline & 2. DTSQ & & & NS \\
\hline & 3. Diabetes attitude scale & & & NS \\
\hline & ( 3 of 7 subscales were included) & & & \\
\hline
\end{tabular}

improvement of $\mathrm{HbA}_{1 \mathrm{c}}$ of $0.24 \%(95 \% \mathrm{CI} 0.03,0.45)$ with SMBG compared to control. ${ }^{14}$ The other 4 well designed studies found no effects of SMBG on glycemic control, but did report a worsening of quality of life parameters compared to control. ${ }^{11-13,16,17,21}$ When comparing the study by Barnett et al with the other well designed studies in order to find a possible explanation for the differences in effects on $\mathrm{HbA}_{1 \mathrm{c}}$, no major differences were found for the interventions used. What was somewhat different in the study by Barnett et al is the shorter diabetes duration and the lower body mass index (BMI) of patients included (Table 1).

Two recent systematic reviews concluded that the effect of SMBG on $\mathrm{HbA}_{1 \mathrm{c}}$ was on average $0.21 \%$ and $0.22 \% .^{15,22}$ One may question, however, whether it is justified to perform a meta-analysis including all the trials, keeping in mind that the benefits of SMBG were found primarily in low quality trials. A Cochrane review did not perform a meta-analysis because of the differences in study quality and because of the differences in baseline data of the patients and type of interventions between the studies. ${ }^{4,34}$

A collaboration of authors of previous trials will investigate whether a certain subgroup of patients can be found who might benefit more from SMBG than the effects found in the systematic reviews. ${ }^{5}$ Perhaps, a short diabetes duration and a low BMI could be factors as hypothesized earlier. On top of that, a large RCT will be performed in the Netherlands including 600 patients with noninsulin-treated T2DM, in which the patients will be randomized into 3 groups: SMBG, self-measurement of urine glucose, and control. ${ }^{35}$ Perhaps, these 2 studies will give some new perspectives about the usefulness of SMBG in certain subgroups of patients. Until then, we recommend that SMBG should not be used generally in a population of noninsulin-treated diabetic patients. Effectiveness on glycemic control has not been established, and quality of life could diminish.

\section{Disclosure}

The author report no conflicts of interest.

\section{References}

1. Goldstein DE, Little RR, Lorenz RA, et al. Tests of glycemia in diabetes. Diabetes Care. 2004;27(7):1761-1773.

2. Nathan DM, McKitrick C, Larkin M, Schaffran R, Singer DE. Glycemic control in diabetes mellitus: have changes in therapy made a difference? Am J Med. 1996;100(2):157-163.

3. Karter AJ, Ackerson LM, Darbinian JA, et al. Self-monitoring of blood glucose levels and glycemic control: the Northern California Kaiser Permanente Diabetes registry. Am J Med. 2001;111(1):1-9.

4. Welschen LM, Bloemendal E, Nijpels G, et al. Self-monitoring of blood glucose in patients with type 2 diabetes who are not using insulin. Cochrane Database Syst Rev. 2005;18(2):CD005060.

5. Farmer AJ, Heneghan C, Barnett AH, et al; Self-monitoring of blood glucose trialists collaboration. Individual patient data meta-analysis of trials of self-monitoring of blood glucose in noninsulin treated type 2 diabetes: Protocol for a systematic review. Prim Care Diabetes. Epub 2009 Apr 15. 
6. Wing RR, Epstein LH, Nowalk MP, Scott N, Koeske R, Hagg S. Does self-monitoring of blood glucose levels improve dietary compliance for obese patients with type II diabetes? $\mathrm{Am} \mathrm{J} \mathrm{Med}$. 1986;81(5):830-836.

7. Scherbaum WA, Ohmann C, Abholz HH, Dragano N, Lankisch M. Effect of the frequency of self-monitoring blood glucose in patients with type 2 diabetes treated with oral antidiabetic drugs-a multi-centre, randomized controlled trial. PLoS ONE. 2008;3(8):e3087.

8. Johnson JA, Majumdar SR, Bowker SL, Toth EL, Edwards A. Self-monitoring in Type 2 diabetes: a randomized trial of reimbursement policy. Diabet Med. 2006;23(11):1247-1251.

9. Siebolds M, Gaedeke O, Schwedes U; SMBG Study Group. Self-monitoring of blood glucose - psychological aspects relevant to changes in $\mathrm{HbA} 1 \mathrm{c}$ in type 2 diabetic patients treated with diet or diet plus oral antidiabetic medication. Patient Educ Couns. 2006; 62(1):104-110.

10. Schwedes U, Siebolds M, Mertes G; SMBG Study Group. Meal-related structured self-monitoring of blood glucose: effect on diabetes control in noninsulin-treated type 2 diabetic patients. Diabetes Care. 2002;25(11):1928-1932.

11. Farmer AJ, Wade AN, French DP, et al; DiGEM Trial Group. Blood glucose self-monitoring in type 2 diabetes: a randomised controlled trial. Health Technol Assess. 2009;13(15):iii-iv, ix-xi, 1-50.

12. Simon J, Gray A, Clarke P, Wade A, Neil A, Farmer A; Diabetes Glycaemic Education and Monitoring Trial Group. Cost effectiveness of self monitoring of blood glucose in patients with noninsulin treated type 2 diabetes: economic evaluation of data from the DiGEM trial. BMJ. 2008;336(7654):1177-1180.

13. Farmer A, Wade A, Goyder E, et al. Impact of self monitoring of blood glucose in the management of patients with noninsulin treated diabetes: open parallel group randomised trial. BMJ. 2007;335(7611):132.

14. Barnett AH, Krentz AJ, Strojek K, et al. The efficicay of self-monitoring of blood glucose in the management of patients with type 2 diabetes treated with a gliclazide modified release-based regimen. A multicentre, randomized, parallel-group, 6-month evaluation (DINAMIC-1 study). Diabetes Obes Metabol. 2008;10:1239-1247.

15. St. John A, Davis WA, Price CP, Davis TM. The value of selfmonitoring of blood glucose: a review of recent evidence. J Diabetes Complications. Epub 2009 Feb 19

16. Allen BT, DeLong ER, Feussner JR. Impact of glucose self-monitoring on noninsulin-treated patients with type II diabetes mellitus. Randomized controlled trial comparing blood and urine testing. Diabetes Care. 1990;13(10):1044-1050.

17. Davidson MB, Castellanos M, Kain D, Duran P. The effect of self monitoring of blood glucose concentrations on glycated hemoglobin levels in diabetic patients not taking insulin: a blinded, randomized trial. Am J Med. 2005;118(4):422-425.

18. Fontbonne A, Billault B, Acosta M, et al. Is glucose self-monitoring beneficial in noninsulin-treated diabetic patients? Results of a randomized comparative trial. Diabete Metab. 1989;15(5):255-260.

19. Guerci B, Drouin P, Grangé V, et al; ASIA Group. Self-monitoring of blood glucose significantly improves metabolic control in patients with type 2 diabetes mellitus: the Auto-Surveillance Intervention Active (ASIA) study. Diabetes Metab. 2003;29(6):587-594.
20. Muchmore DB, Springer J, Miller M. Self-monitoring of blood glucose in overweight type 2 diabetic patients. Acta Diabetol. 1994;31(4):215-219.

21. O'Kane MJ, Bunting B, Copeland M, Coates VE; ESMON study group. Efficacy of self monitoring of blood glucose in patients with newly diagnosed type 2 diabetes (ESMON study): randomised controlled trial. BMJ. 2008;336(7654):1174-1177.

22. Towfigh A, Romanova M, Weinreb JE, et al. Self-monitoring of blood glucose levels in patients with type 2 diabetes mellitus not taking insulin: a meta-analysis. Am J Manag Care. 2008;14(7):468-475.

23. McGeoch G, Derry S, Moore RA. Self-monitoring of blood glucose in type-2 diabetes: what is the evidence? Diabetes Metab Res Rev. 2007;23(6):423-440.

24. Welschen LM, Bloemendal E, Nijpels G, et al. From the Cochrane Library and Diabetes Care: self-monitoring of blood glucose probably an effective way to improve glycaemic control in patients with type 2 diabetes not taking insulin. Ned Tijdschr Geneeskd. 2006;150(33):1826-1829.

25. Jansen JP. Self-monitoring of glucose in type 2 diabetes mellitus: a Bayesian meta-analysis of direct and indirect comparisons. Curr Med Res Opin. 2006;22(4):671-681.

26. Saudek CD, Derr RL, Kalyani RR. Assessing glycemia in diabetes using self-monitoring blood glucose and hemoglobin $\mathrm{A}_{1 \mathrm{c}}$. JAMA. 2006;295(14):1688-1697.

27. Home glucose monitoring makes little difference in type 2 diabetes J Fam Pract. 2005;54(11):936.

28. Welschen LM, Bloemendal E, Nijpels G, et al. Self-monitoring of blood glucose in patients with type 2 diabetes who are not using insulin: a systematic review. Diabetes Care. 2005;28(6):1510-1517.

29. Sarol JN Jr, Nicodemus NA Jr, Tan KM, Grava MB. Self-monitoring of blood glucose as part of a multi-component therapy among noninsulin requiring type 2 diabetes patients: a meta-analysis (1966-2004). Curr Med Res Opin. 2005;21(2):173-184.

30. Holmes V, Griffiths P. Self-monitoring of glucose levels for people with type 2 diabetes. Br J Community Nurs. 2002;7(1):41-46.

31. Coster S, Gulliford MC, Seed PT, Powrie JK, Swaminathan R. Selfmonitoring in Type 2 diabetes mellitus: a meta-analysis. Diabet Med. 2000;17(11):755-761.

32. Coster S, Gulliford MC, Seed PT, Powrie JK, Swaminathan R. Monitoring blood glucose control in diabetes mellitus: a systematic review. Health Technol Assess. 2000;4(12):i-iv, 1-93.

33. Faas A, Schellevis FG, Van Eijk JT. The efficacy of self-monitoring of blood glucose in NIDDM subjects. A criteria-based literature review. Diabetes Care. 1997;20(9):1482-1486.

34. Kleefstra N, Houweling ST, van Ballegooie E, Bilo HJ. Selfmonitoring of blood glucose in patients with type 2 diabetes who are not using insulin: response to Welschen et al. Diabetes Care. $2005 ; 28(10): 2596$.

35. Malanda UL, Bot SD, Kostense PJ, Snoek FJ, Dekker JM, Nijpels G. Effects of self-monitoring of glucose in noninsulin treated patients with type 2 diabetes: design of the IN CONTROL-trial. BMC Fam Pract. 2009;10(1):26

Diabetes, Metabolic Syndrome and Obesity: Targets and Therapy

\section{Publish your work in this journal}

Diabetes, Metabolic Syndrome and Obesity: Targets and Therapy is an international, peer-reviewed open-access journal committed to the rapid publication of the latest laboratory and clinical findings in the fields of diabetes, metabolic syndrome and obesity research Original research, review, case reports, hypothesis formation, expert

\section{Dovepress}

opinion and commentaries are all considered for publication. The manuscript management system is completely online and includes a very quick and fair peer-review system, which is all easy to use. Visit http://www.dovepress.com/testimonials.php to read real quotes from published authors. 